\title{
Aplikasi Pembaca Tunanetra Menggunakan Smartphone Android
}

\author{
Fajar Hermawanto ${ }^{1}$, Sri Ariyanti Sabiku ${ }^{2}$, Maryam Dai ${ }^{3}$ \\ ${ }^{1}$ fajar@poligon.ac.id. ${ }^{2}$ riantisabiku@poligon.ac.id. ${ }^{3}$ maryam.mhs16@ti.poligon.ac.id. \\ Prodi D3 Teknik Informatika Politeknik Gorontalo, \\ Panggulo Barat, Botupingge, Kabupaten Bone Bolango, Gorontalo 92112
}

\begin{abstract}
Abstrak - Dalam mengakses informasi penyandang tunanetra berbeda dengan manusia pada umumnya. Jika orang normal hanya dengan melihat yang ada disekelilingnya mereka akan memperoleh banyak informasi, namun bagi penyandang tunanetra mereka harus menggunakan indera peraba dan indera pendengar. Untuk memperoleh informasi visual(teks), penyandang tunanetra menggunakan bahan bacaan yang dicetak dalam tulisan Braille (huruf timbul yang diraba). Akan tetapi ketersediaan informasi teks dalam bentuk Braille ini sangat terbatas. Keterbatasan informasi dalam bentuk Braille, menjadi kendala bagi penderita tunanetra disaat ingin mengetahui informasi yang terdapat dalam bentuk surat kabar, majalah, bulletin dan sebagainya. Selain itu penyandang tunanetra sangat membutuhkan informasi melalui media visual. Khusus untuk tulisan atau teks disediakan dalam bentuk Braille. Berdasarkan masalah diatas, maka dibuat suatu Aplikasi Pembaca Tunanetra menggunakan Smartphone Android. Hal ini dapat mempermudah penyandang tunanetra dalam memperoleh informasi visual (teks). Dengan adanya aplikasi yang akan dibuat ini diharapkan dapat membantu dan mempermudah penyandang tunanetra dalam memperoleh informasi visual (teks).
\end{abstract}

Abstract - In accessing information that is blind, this is different from humans in general. If normal people only see what is around them, they will get a lot of information, but for blind people they must use the sense of touch and the sense of the listener. To get visual information (text), the blind use reading material that is printed in Braille writing (embossed letters). However, the availability of text information in the form of Braille is very limited. Information contained in newspapers, magazines, bulletins and so on. Besides blind people are in dire need of information through visual media. Especially for writing or text provided in the form of Braille. The Blind Reader application was created using an Android Smartphone. This can make it easier for blind people to obtain visual information (text). With the application made, it is expected to help and facilitate blind people in obtaining visual information(text).

Kata Kunci: Aplikasi, Tunanetra, Informasi, Braille.

\section{PENDAHULUAN}

\section{A. Latar belakang}

Era sekarang ini informasi akan semakin dibutuhkan seiring dengan perkembangan zaman. Informasi merupakan salah satu hal yang penting bagi masyarakat pada era teknologi seperti sekarang ini. Masa kejayaan informasi saat ini menjadikan informasi semakin hari semakin cepat berkembang dan berganti, sehingga masyarakat bisa tertinggal akan informasi dalam hitungan menit atau bahkan detik. Akan tetapi, bagaimana dengan penyandang tunanetra yang mempunyai kesulitan dalam hal membaca. Indera penglihatan merupakan salah satu sumber informasi vital bagi manusia, karena dapat dikatakan sebagian besar informasi yang diperoleh oleh manusia berasal dari indera penglihatan[1]. Oleh karena itu dapat dipahami ketika seseorang mengalami gangguan penglihatan maka kemampuan aktivitasnya semakin terbatas. Karena informasi yang diperoleh akan jauh berkurang dibandingkan dengan orang normal.

SLB Negeri Bone Bolango merupakan sekolah yang mempunyai siswa berkebutuhan khusus tunanetra. Disekolah tersebut memiliki fasilitas yang dapat diakses oleh siswa tunanetra untuk memenuhi kebutuhan infromasi. Salah satunya yaitu koleksi buku Braille. Sumber informasi koleksi buku Braille tersebut berupa informasi akademik yang berhubungan dengan mata pelajaran di sekolah.

Pada observasi awal kondisi SLB kurang maksimal dalam memenuhi kebutuhan informasi karena dilihat dari minimnya penggunaan koleksi buku Braille. Hal tersebut didasarkan pada wawancara dengan Guru khusus penyandang tunanetra bahwa siswa tunanetra mulai mengesampingkan koleksi buku Braille karena mereka lebih memilih menggunakan rekaman audio untuk mendapatkan informasi dalam kesehariannya disekolah. Kemudian dalam penggunanaan buku Braille tidak semua guru menguasai baca tulis Braille. Biasanya untuk guru sendiri dalam membantu siswa membacakan huruf Braille dengan cara melihat tidak dengan meraba karena keterbatasan pemahaman mengenai huruf Braille.

Selain itu penyandang tunanetra sangat membutuhkan informasi melalui media visual. Informasi secara visual pada umumnya disampaikan melalui video, gambar, tulisan/teks. Khusus untuk tulisan atau teks disediakan dalam bentuk Braille 
Akan tetapi ketersediaan informasi teks dalam bentuk Braille sangat terbatas. Keterbatasan informasi dalam bentuk Braille, menjadi kendala bagi penderita tunanetra disaat ingin mengetahui informasi yang terdapat dalam bentuk surat kabar, majalah, bulletin dan sebagainya.

Berdasarkan permasalahan tersebut, maka diperlukan suatu aplikasi yang dapat membantu menerima informasi secara visual teks dan menyampaikannya dalam bentuk suara, agar dapat diterima penderita tunanetra melalui indera pendengarannya. Aplikasi yang diperlukan harus berliput mobile agar lebih mudah digunakan dimana saja. Maka dari itu peneliti akan membuat Aplikasi Pembaca Tunanetra Menggunakan Smartphone Android.

\section{B. Rumusan masalah}

Berdasarkan latar belakang yang dikemukakan terdahulu, maka rumusan masalah yang akan dibahas dalam penelitian adalah bagaimana cara merubah informasi visual (teks) agar dapat diterima penyandang tunanetra.

\section{Tujuan}

Tujuan dari penelitian ini adalah untuk membuat suatu Aplikasi Pembaca Tunanetra Menggunakan Smartphone Android, yang dapat merubah informasi visual (teks) ke audio agar dapat diterima penyandang tunanetra melalui indera pendengaran.

\section{Manfaat}

Adapun manfaat penelitian yang bisa diambil dari penelitian ini adalah:

1. Mempermudah penyadang tunanetra dalam mengakses informasi dalam bentuk teks.

2.Penyandang tunanetra tidak lagi membutuhkan waktu yang lama dalam memperoleh informasi.

\section{KAJIAN PUSTAKA}

\section{A. Penelitian Terdahulu}

Dalam penelitian terdahulu ini peneliti dapat melihat perbedaan antara penelitian yang telah dilakukan dengan penelitian yang dilakukan. Selain itu juga, diharapkan dalam penelitian ini dapat diperhatikan mengenai kekurangan dan kelebihan antara penelitian terdahulu dengan penelitian yang dilakukan.

Penelitian sejenis yang pernah dilakukan oleh Aldi Setiawan, Herry Sujaini dan Arif Bijaksana yang berjudul "Implementasi Optical Character Recognition (OCR) Pada Mesin Penerjemah Bahasa Indonesia ke Bahasa Inggris"[2].

Dari penelitian terdahulu dapat ditarik kesimpulan bahwa perbedaannya dengan penelitian yang dilakukan oleh peneliti adalah pada penerjemahannya, jika pada penelitian terdahulu menggunakan mesin penerjemah translation model, maka peneliti menggunakan language model.

\section{B. Tunanetra}

Tunanetra adalah mereka yang tidak memiliki penglihatan sama sekali atau mereka yang masih memiliki sisa penglihatan namun tidak mampu menggunakan penglihatannya[3].

Seseorang dikatakan buta secara fungsional apabila saluran utama yang dipergunakannya dalam belajar adalah perabaan atau pendengaran. Mereka dapat mempergunakan sedikit sisa penglihatannya untuk memperoleh informasi tambahan dari lingkungan. Orang seperti ini biasanya mempergunakan huruf Braille sebagai media membaca dan memerlukan latihan orientasi dan mobilitas.

\section{Braille}

Braille adalah sejenis sistem tulisan sentuh yang digunakan oleh penyandang tunanetra. Sistem ini diciptakan oleh seorang Perancis yang bernama Louis Braille yang buta disebabkan kebutaan waktu kecil, tulisan ini dinamakan huruf Braille. Melalui perjalanan yang panjang, tulisan Braille sekarang telah diakui efektifitasnya dan diterima sebagai tulisan yang digunakan oleh tunanetra di seluruh dunia. Selain itu huruf Braille bukan saja sebagai alat komunikasi bagi para tunanetra tetapi juga sebagai representasi suatu kompetensi, kemandirian, dan juga persamaan 


\section{Android}

Android adalah salah satu sistem operasi yang pada awalnya, kemudian berkembang menjadi bahasa pemrograman yang banyak dicari dan digunakan oleh para programmer. Pada dasarnya android adalah sistem operasi berbasis linux. Penggunaan android pada awalnya hanya digunakan untuk melengkapi sistem operasi pada gadget-gadget seluler seperti smartphone yang menggunakan layar sentuh. Tetapi karena sistem yang dikembangkan open source, mau tidak mau perkembangan dan penerimaan di dunia industry IT menjadi lebih cepat juga[4].

\section{E. OCR (Optical Character Recognition)}

Kegunanaan dari OCR (Optical Character Recognition) yaitu untuk menscan gambar pada image dan dijadikan text, dengan adanya OCR, image yang bertuliskan tangan, tulisan mesin ketik atau komputer teks, dapat dimanipulasi.

Optical Character Recognition (OCR) merupakan suatu metode yang memecahkan masalah pengenalan karakter baik karakter teks mesin ketik, teks komputer maupun tulisan tangan yang terkandung dalam suatu citra. Metode OCR saat ini sudah banyak dimanfaatkan dalam aplikasi translator mobile pada smartphone, dimana inputnya berupa citra yang mengandung karakterkarakter untuk diterjemahkan ke dalam beberapa bahasa.

Optical Character Recognition (OCR) dalam arti luas merupakan cabang dari artificial intelligence dan computer vision. OCR adalah sebuh aplikasi komputer yang digunakan untuk mengidentifikasi citra huruf maupun angka untuk konversi ke dalam bentuk file tulisan. Sistem pengenalan huruf ini dapat meningkatkan fleksibilitas atau kemampuan dan kecerdasan komputer. Sistem pengenal huruf yang cerdas sangat membantu usaha digitalisasi informasi dan pengetahuan, Misalnya dalam pembuatan koleksi pustaka digital, Koleksi sastra kuno dan lain-lain[5].

\section{F. $\quad$ Unified Modeling Language(UML)}

Uml digunakan untuk membuat model logika dari suatu sistem dan digunakan untuk mengembangkan sistem agar mudah dipahami selama fase desain. UML biasanya disajikan dalam bentuk diagram dan notasi-notasi yang membantu memodelkan sistem dari berbagai perspektif.

Unified modeling Language (UML) adalah bahasa spesifikasi standard yang dipergunakan untuk mendokumentasikan, menspesifikasikan dan membangun perangkat lunak. UML merupakan metodologi dalam mengembangkan sistem berorientasi objek dan juga merupakan alat untuk mendukung pengembangan sistem[6].

\section{III. .METODOLOGI PENELITIAN}

\section{A. Analisis Data}

Jenis penelitian yang digunakan menggunakan metode wawancara. Wawancara adalah proses memperoleh keterangan untuk tujuan penelitian dengan tanya jawab sambil bertatap muka antara orang yang mewawancarai.

Metode wawancara berfungsi sebagai data primer, pelengkap atau sebagai kriteria. Sebagai data primer, data yang diperoleh dari wawancara merupakan data yang utama guna menjawab permasalahan penelitian. Sebagai metode pelengkap, wawancara berfungsi sebagai pelengkap metode lainnya yang digunakan untuk menguji mengumpulkan data pada setiap penelitian.

Wawancara merupakan metode pengumpulan data dengan jalan tanya jawab sepihak yang dilakukan dalam penelitian ini yaitu mewawancarai Ibu Fitria Talamati selaku guru penyandang tunanetra di Sekolah Luar Biasa Bone Bolango. 


\section{B. Analisis Sistem Berjalan}

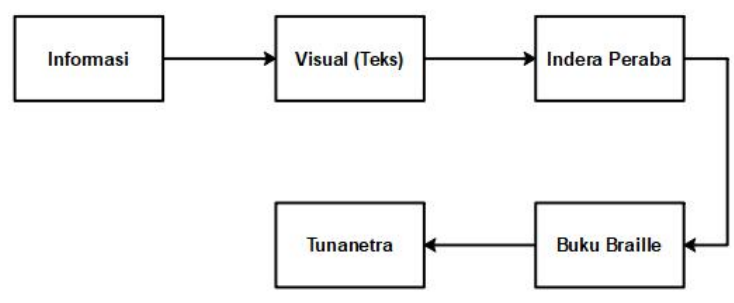

Gambar.1 Sistem Berjalan Pembaca Tunanetra

Deskripsi rancangan Aplikasi Pembaca Tunanetra menggunakan Smartphone Android, dimana pada gambar tersebut dijelaskan bahwa dalam memperoleh informasi penyandang tunanetra terhambat karena keterbatasan dalam indera penglihatan. Oleh karena itu dalam memperoleh informasi penyandang tunanetra mengandalkan indera yang lain yaitu indera peraba. Indera peraba digunakan untuk memperoleh informasi dalam bentuk buku Braille.

Braille dapat memudahkan penyandang tunanetra untuk berlatih mengakses informasi secara mandiri melalui tulisan khusus bagi mereka. Namun penyandang tunanetra mulai mengesampingkan koleksi buku Braille karena lebih memilih menggunakan rekaman audio untuk mendapatkan informasi dalam kesehariannya. Analisis Sistem

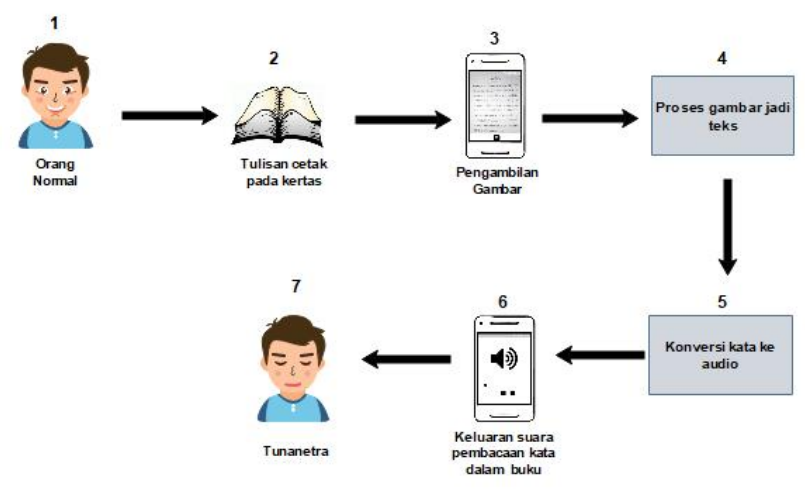

Gambar.2 Sistem Usulan Pembaca Tunanetra

Deskripsi rancangan Aplikasi Pembaca Tunanetra Menggunakan Smartphone Android adalah

1. Dalam memperoleh informasi yang terdapat dalam tulisan cetak pada kertas tunanetra dibantu oleh orang normal.

2. Terdapat tulisan cetak pada kertas.

3. Kemudian pengambilan gambar pada tulisan cetak pada kertas dibantu oleh orang normal.

4. Setelah itu proses gambar jadi teks.

5. kemudiangambar yang telah dikonversi menjadi teks akan dikonversi lagi menjadi audio tetapi perkata.

6. Keluar suara hasil dari tulisan yang di capture tetapi perkata. 


\section{Use Case Diagram}

Use case dibawah ini merupakan penjelasan fungsional keselurahan dari Aplikasi Pembaca Tunaanetra Menggunkan Smartphone Android yang akan dibangun.

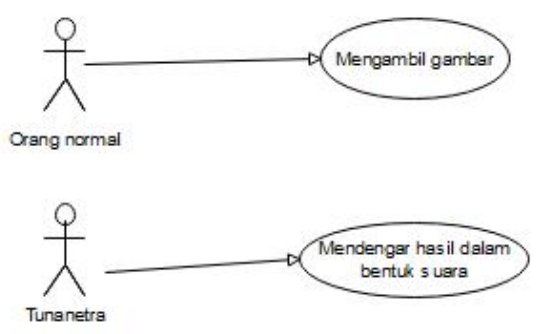

Gambar.3 Use Case Diagram Rancangan Sistem

Use case pada gambar 3 berikut merupakan uraian antar muka (Use Interface), atau gambaran umum kegiatan yang akan dilakukan oleh pengguna aplikasi membaca tunanetra menggunakan smartphone android. Deskripsi dari gambar 3 adalah sebagai berikut:

Untuk pengambilan gambar yang terdapat pada tulisan cetak pada kertas tunanetra dibantu oleh orang normal, jadi tunaentra hanya langsung bisa mendengar informasi yang terdapat pada tulisan cetak tersebut. Kerena dalam pengambilan gambar dibantu oleh orang normal.

\section{Activity Diagram}

Menggambarkan aktifitas-aktifitas, objek, state, transisi state dan event. Dengan kata lain kegiatan diagram alur kerja menggambarkan perilaku sistem.

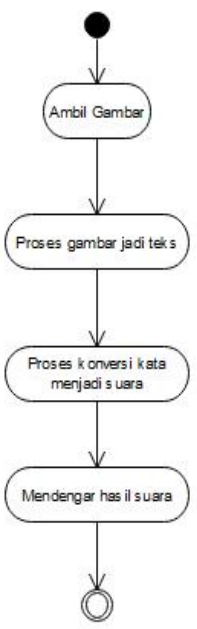

Gambar 4. Activity Diagram Pengguna

Pada gambar tersebut menjelaskan bahwa aktifitas terjadi antara aktor Pengguna dan Sistem.

Deskripsi dari gambar 4 adalah sebagai berikut:

1. Aktifitas dimulai dari pengguna melakukan pengambilan gambar berupa teks/tulisan menggunakan kamera.

2. Setelah itu hasil dari gambar berupa teks yang telah diambil menggunakan kamera akan di proses menjadi teks.

3. Setelah gambar diproses menjadi teks maka akan langsung keluar hasil dalam bentuk suara.

4. Penyandang tunanetra dapat mendengar hasil suara dari gambar teks pada kertas yang telah diambil. 


\section{E. Sequence Diagram}

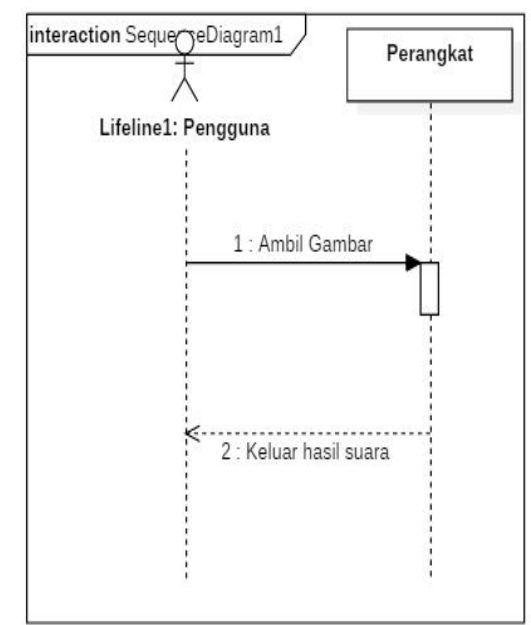

Gambar 5. Sequence Diagram Pengguna

Gambar 4 merupakan sequence diagram aktor pengguna.

Deskripsi dari gambar tersebut adalah sebagai berikut:

1. Pengguna melakukan pengambilan gambar berupa teks/tulisan menggunakan kamera, kemudian hasil dari gambar tersebut akan dikonversi ke teks, setelah itu akan dikoversi lagi ke audio.

2. Penyandang tunanetra bisa mendengar hasil suara yang telah di konversi dari gambar berupa teks tersebut.

\section{IMPLEMENTASI}

\section{Hasil Penelitian}

Setelah sistem dianalisis dan di desain secara rinci, maka akan dilanjutkan ketahap implementasi yang menerapkan hasil analisis sistem kesebuah aplikasi. Implementasi sistem merupakan kumpulan dari elemen-elemen yang telah di desain ke dalam bentuk pemrograman untuk menghasilkan suatu tujuan yang dibuat berdasarkan kebutuhan.

\section{Tampilan Utama Aplikasi}

Tampilan utama pada aplikasi ini yaitu berupa menu camera, kemudian hasil serta tampilan gambar.

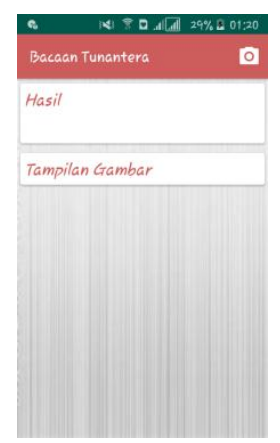

Gambar 6. Tampilan Utama Aplikasi

\section{Keterangan:}

Pada tampilan ini pengguna dapat mengklik menu camera untuk pengambilan gambar berupa teks, kemudian untuk hasil dan tampilan gambar pada halaman ini yaitu, hasil untuk output dari proses gambar yang telah di ubah menjadi teks dan tampilan gambar untuk menampilkan hasil gambar yang telah di ambil. 
Tampilan Pengambilan Gambar

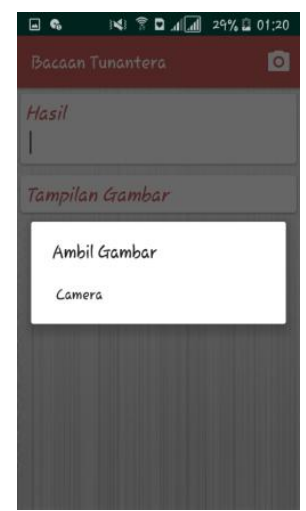

Gambar 7. Tampilan Pengambilan Gambar

Keterangan:

Setelah pengguna mengklik menu camera yang terdapat pada halaman utama maka akan muncul tampilan pengambilan gambar mengguanakan camera.

Tampilan Hasil Pengambilan Gambar

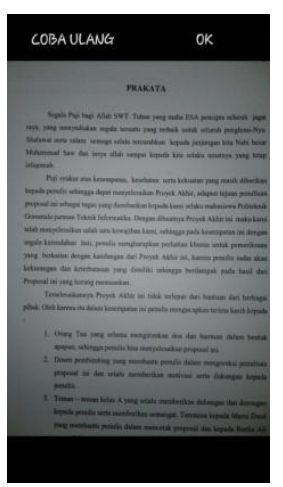

Gambar 8. Hasil Pengambilan Gambar

Keterangan:

Tampilan ini adalah hasil dari Pengambilan Gambar Teks, untuk pengambilan gambar harus di fokuskan karena itu akan memperngaruhi proses gambar menjadi teks. Jika hasil dari pengambilan gambar belum bagus maka pengguna bisa melakukan pengambilan gambar lagi dengan mengklik coba ulang. Tapi jika hasil gambar sudah bagus maka langsung saja mengklik ok.

Tampilan Crop

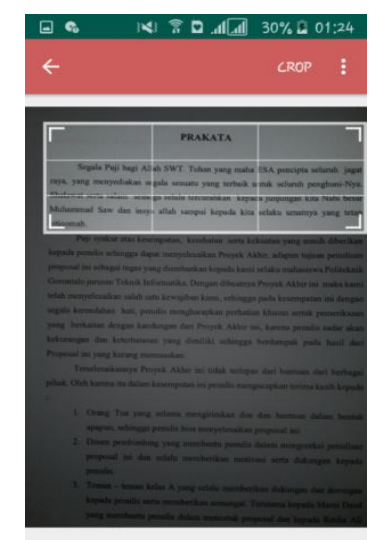

Gambar 9. Tampilan Crop

Keterangan: 
Tampilan ini yaitu untuk memotong bagian gambar mana yang akan diambil, setelah itu langsung saja klik Crop. Untuk proses gambar menjadi teks.

Keterangan:

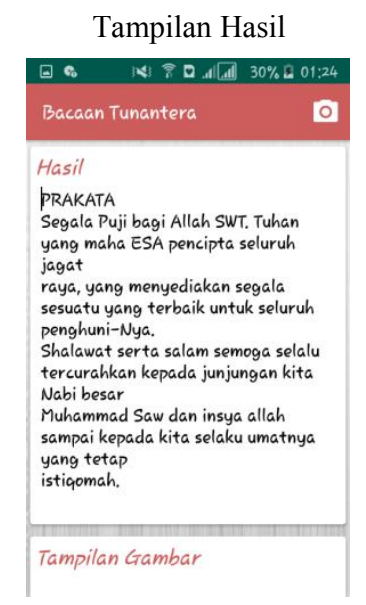

Gambar 10. Tampilan Hasil

Pada tampilan ini adalah Hasil dari Gambar teks yang telah pengguna ambil yang telah diproses menjadi teks kemudian di konversi lagi menjadi keluaran suara. Agar dapat diterima oleh Tunanetra.

\section{PENUTUP \\ Kesimpulan}

Aplikasi Pembaca Tunanetra Menggunakan Smartphone Android ini mempermudah penyandang tunanetra dalam mengakses informasi, penerapan aplikasi pembaca tunanetra ini hanya dikhususkan kepada penyandang tunanetra saja, penggunaan aplikasi ini untuk memberikan sebuah informasi dalam bentuk teks bacaan yang akan diubah ke suara atau audio. Sehingganya penyandang tunanetra ini dapat menerima sebuah informasi melalui indera pendengarannya.

\section{Saran}

Berdasarkan hasil pengujian Aplikasi Pembaca Tunanetra Menggunakan Smartphone Android dapat diberikan beberapa saran sebagai berikut. Perlu dilakukan penelitian lebih lanjutan untuk mengembangkan Aplikasi Pembaca Tunanetra Menggunakan Smartphone Android. Adapun yang perlu di tambahkan dalam Aplikasi ini adalah pengambilan gambar dilakukan berulang kali minimal lima gambar, setelah itu bisa diproses menjadi teks dengan keluaran suara, kemudian di buatkan tampilan slide pada masing masing gambar yang akan di tampilkan. Sehingga aplikasi ini dapat dipergunakan sesuai dengan kebutuhan pengguna.

\section{DAFTAR PUSTAKA}

[1]. Y. Sekar and M. Rachmawati, "Perancangan Pusat Komunitas Tunanetra Indonesia dengan Pendekatan Indera," JURNAL SAINS DAN SENI ITS Vol. 5, No.2, (2016).

[2]. J. Sistem and I. Justin, "IMPLEMENTASI OPTICAL CHARACTER RECOGNITION ( OCR ) PADA MESIN PENERJEMAH,” Jurnal Sistem dan Teknologi Informasi (JUSTIN) Vol. 5, No. 2, (2017).

[3]. R. M. Nahlisa and L. Christiani, "BUKU BRAILE SEBAGAI JEMBATAN KETERBATASAN AKSES INFORMASI SISWA TUNANETRA SEKOLAH LUAR BIASA BAGIAN A DRIA ADI SEMARANG," Jurnal Ilmu Perpustakaan Vol. 4, No. 2 (2015).

[4]. M. Ichwan, and F. Hakiky, "PENGUKURAN KINERJA GOODREADS APPLICATION PROGRAMMING INTERFACE (API) PADA APLIKASI MOBILE ANDROID (Studi Kasus Untuk Pencarian Data Buku) “, Jurnal informatika, vol. 2, no. 2, pp. 13-21.

[5]. R. Jana and A. R. Chowdhury, “Optical Character Recognition from Text Image," International Journal of Computer Applications Technology and Research, vol. 3, no. 4, pp. 239-243, 2014.

[6]. A. Kinerja et al., "Implementasi Diagram UML (Unified Modeling Language) Pada Perancangan Sistem Informasi Remunerasi Dosen Dengan Database Oracle,” Jurnal Ilmu Komputer dan Informatika, vol. 6341, no. November, pp. 1-9, 2018. 